\title{
Copy number variations associated with fetal congenital kidney malformations
}

\author{
Meiying Cai ${ }^{\dagger}, \mathrm{Na}$ Lin $^{\dagger}$, Linjuan Su, Xiaoqing Wu, Xiaorui Xie, Ying Li, Xuemei Chen, Yuan Lin, Hailong Huang ${ }^{*}$ and \\ Liangpu $\mathrm{Xu}^{*}$
}

\begin{abstract}
Background: Congenital anomalies of the kidney and urinary tract (CAKUT) constitute 20-30\% of all congenital malformations. Within the CAKUT phenotypic spectrum, renal hypodysplasia (RHD) is particularly severe. This study aimed to evaluate the applicability of single-nucleotide polymorphism (SNP) array test in prenatal diagnosis of RHD for improving prenatal genetic counseling and to search for evidence of a possible causative role of copy-number variations (CNVs) in RHD.
\end{abstract}

Results: We performed a systematic survey of CNV burden in 120 fetuses with RHD: 103 cases were isolated RHD and 17 were non-isolated RHD. Single-nucleotide polymorphism (SNP) array test was performed using the Affymetrix CytoScan HD platform. All annotated CNVs were validated by fluorescence in situ hybridization. We identified abnormal CNVs in 15 (12.5\%) cases of RHD; of these CNVs, 11 were pathogenic and 4 were variants of uncertain significance. The detection rate of abnormal CNVs in non-isolated RHD was higher $(29.4 \%, 5 / 17)$ than that in isolated RHD $(9.7 \%, 10 / 103)(P=0.060)$. Parents are more inclined to terminate the pregnancy if the fetuses have pathogenic results of the SNP-array test.

Conclusions: The variable phenotypes that abnormal CNVs may cause indicate the genetic counseling is needed for RHD cases.

Keywords: Copy-number variations, Etiology, Chromosomal microarray analysis, Renal hypodysplasia

\section{Background}

Congenital anomalies of the kidney and urinary tract (CAKUT) constitute $20-30 \%$ of all congenital malformations, and their prevalence is between three and seven per 1000 births [1]. These malformations account for $40-50 \%$ of children's kidney diseases and $7 \%$ of adult end-stage kidney diseases worldwide [2]. Within the CAKUT phenotypic spectrum, renal aplasia, agenesis, hypoplasia, and dysplasia (referred as renal hypodysplasia [RHD]) [3] are particularly severe conditions, affecting $0.5 \%$ of the general population [4]. The etiology of

\footnotetext{
* Correspondence: hl-hai@163.com; xiliangpu@fjmu.edu.cn

${ }^{\dagger}$ Meiying Cai and $\mathrm{Na}$ Lin contributed equally to this work.

Department of the Prenatal Diagnosis Center, Fujian Provincial Maternity and Children's Hospital, affiliated hospital of Fujian Medical University, Fujian Key Laboratory for Prenatal Diagnosis and Birth Defect, Fuzhou, China
}

the majority of RHD cases remains unknown. However, many studies suggest that the pathogenesis of these birth defects is related to strong genetic factors.

Exploring the potential genetic etiology of congenital anomalies can establish a genetic diagnosis and/or improve the management of possible complications. A few postnatal cases with congenital RHD have been reported to be associated with CNVs [3], which drew our attention to the underlying utility of SNP-array test in the prenatal diagnosis of congenital RHD; we came up with the idea that it could be a genetic disease rather than a sporadic one. Thus, the prognosis of congenital RHD may not be as good as initially believed. In this study, we performed a systematic investigation of abnormal CNVs in fetuses with congenital RHD using Chromosomal Microarray Analysis (CMA).

C C The Author(s). 2020 Open Access This article is licensed under a Creative Commons Attribution 4.0 International License, which permits use, sharing, adaptation, distribution and reproduction in any medium or format, as long as you give appropriate credit to the original author(s) and the source, provide a link to the Creative Commons licence, and indicate if changes were made. The images or other third party material in this article are included in the article's Creative Commons licence, unless indicated otherwise in a credit line to the material. If material is not included in the article's Creative Commons licence and your intended use is not permitted by statutory regulation or exceeds the permitted use, you will need to obtain permission directly from the copyright holder. To view a copy of this licence, visit http://creativecommons.org/licenses/by/4.0/ The Creative Commons Public Domain Dedication waiver (http://creativecommons.org/publicdomain/zero/1.0/) applies to the data made available in this article, unless otherwise stated in a credit line to the data. 


\section{Methods}

\section{Patient data}

We conducted a retrospective study on RHD cases diagnosed prenatally by fetal ultrasound from the Prenatal Diagnosis Center of Fujian Provincial Maternal and Children Health Hospital, between January 2016 and July 2019. The inclusion criteria included the presence of a renal parenchymal defect such as renal agenesis or renal dysplasia (discovery of a small or cystic kidney for gestational age kidneys) (seven cases have been previously included in our papers such as case 1 , case 2 , case 8 , case 9 , case 12 , case 13 , and case 15 ) [5].

A total of 120 RHD cases were included: 103 cases of isolated RHD and 17 cases of non-isolated RHD. All included cases underwent invasive prenatal genetic testing, and we preserved qualified DNA samples. Isolated RHD was defined as a renal parenchymal defect such as renal agenesis, hypoplasia, or dysplasia. Non-isolated RHD was defined as RHD with the presence of significant extra-renal malformations. Extra-renal malformations detected in non-isolated RHD cases included cardiac defects (e.g., ventricular septal defect, aortic stenosis, pulmonary valve stenosis, persistent left superior vena cava, tricuspid regurgitation), urorectal septum malformation sequence (URSMS), fetal growth restriction (FGR), nasal bone dysplasia, and single umbilical artery. Approximately $2.0 \mathrm{~mL}$ of peripheral venous blood in ethylenediaminetetraacetic acid (EDTA) was collected from the parents if the RHD fetal CNVs detected were considered rare. DNA was extracted using a Gentra Puregene Blood Kit (Qiagen, Hilden, Germany).

Amniocentesis (in 74 cases) and umbilical cord blood collection (in 46 cases) were performed, according to gestational age. Amniotic fluid was collected by amniocentesis at 16-24 weeks of gestation, and fetal blood was collected by cordocentesis after 24 weeks of gestation [5]. The fetuses underwent routine ultrasonic scans, and fetal biometry was assessed at a median gestational age of $24 \pm 6$ weeks (range: $18 \pm 2$ to $34 \pm 1$ weeks). Clinical follow-up was assessed by physical examination and postpartum ultrasound.

\section{Single-nucleotide polymorphism array}

Single-nucleotide polymorphism (SNP) array technology was performed as previously reported by our laboratory [6]. The CNVs were classified into three categories: pathogenic, variants of uncertain clinical significance (VUS), and benign, according to the American College of Medical Genetics guidelines [7]. Parental testing was performed for fetuses with RHD that had abnormal SNP-array results to determine the inheritance pattern of the deletions and/or duplications. All annotated $\mathrm{CNVs}$ were experimentally validated by fluorescence in situ hybridization.

\section{Statistical analysis}

Statistical analysis was performed with SPSS version 20 (IBM, Armonk, NY, USA). Comparisons between isolated RHD and RHD associated with other anomalies were performed using the Fisher's exact test. A $P$ value $<0.05$ was considered statistically significant.

\section{Results}

A total of 120 RHD cases were included, of which $103(85.8 \%)$ cases were isolated RHD and 17 (14.2\%) were non-isolated RHD (Table 1 ). We identified abnormal CNVs in 15 (12.5\%) cases of RHD; of these 15 CNVs, 11 were pathogenic and 4 were VUS. We also detected two benign CNVs. The detection rate of abnormal CNVs in the non-isolated RHD cases was higher $(29.4 \%, 5 / 17)$ than that in the isolated RHD cases $(9.7 \%, 10 / 103)(P=0.060)$.

\section{Abnormal CNVs in fetuses with isolated RHD}

Of the 103 cases of isolated RHD, 7 were pathogenic and 3 were VUS. The CMA nomenclature, pathogenic renal genes, and inheritance status are described in Table 2. Seven pathogenic CNVs (one 22q11.2 deletion, four $17 \mathrm{q} 12$ deletion, one $17 \mathrm{p} 12$ deletion, and one $3 \mathrm{q} 28$ deletion) were identified in seven fetuses with isolated RHD. We detected a de novo 22q11.21 deletion in case 1 , which had an ectopic right kidney with dysplasia deformations.

Three VUS CNVs were identified in fetuses with isolated RHD. We found case 8 with a 9q21.31q21.32 deletion in a region including the TLE1 gene [8]. At 20 weeks of gestation, this case presented with left renal dysplasia, and the finding was regarded as VUS. At 22 weeks, case 9 presented with renal dysplasia, and its SNP-array test showed a partial duplication of 2q31q34. At 27 weeks of gestation, we identified case 10 with isodisomy, but the ultrasonic diagnosis was presented with right renal dysplasia.

\section{Abnormal CNVs in fetuses with non-isolated RHD}

In the fetuses with non-isolated RHD, the SNP-array test identified clinically significant pathogenic CNVs, involving the isodisomy in $16 \mathrm{q} 23.2 \mathrm{q} 24.3$ and $16 \mathrm{p} 13.3 \mathrm{p} 12.3$,

Table 1 Phenotypic characteristics of 120 renal hypodysplasia fetuses

\begin{tabular}{|c|c|c|c|c|}
\hline \multirow[t]{2}{*}{ Classification } & \multirow{2}{*}{$\begin{array}{l}\text { Number } \\
\text { of } \\
\text { fetuses }\end{array}$} & \multicolumn{3}{|l|}{ Number of CMA } \\
\hline & & Pathogenic CNVs & VUS & Benign \\
\hline Isolated RHD & 103 & 7 & 3 & 2 \\
\hline Non-isolated RHD & 17 & 4 & 1 & 0 \\
\hline Total & 120 & 11 & 4 & 2 \\
\hline
\end{tabular}

VUS Variation of uncertain clinical significance 
Table 2 Ten abnormal copy-number variations detected in fetuses with isolated renal hypodysplasia

\begin{tabular}{|c|c|c|c|c|c|c|}
\hline case & CMA results & $\begin{array}{l}\text { Size } \\
(M b)\end{array}$ & Renal phenotype & $\begin{array}{l}\text { Pathogenicity } \\
\text { classification }\end{array}$ & $\begin{array}{l}\text { Obstetrical } \\
\text { outcomes }\end{array}$ & Inheritance \\
\hline 1 & arr [hg19]22q11.21 $(18,916,842-21,800,471) \times 1$ & 2.8 & $\begin{array}{l}\text { ectopic right kidney with } \\
\text { dysplasia }\end{array}$ & $p$ & $\mathrm{TP}$ & de novo \\
\hline 2 & $\operatorname{arr}[$ hg 19]17q12(34,822,465-36,311,009) × 1 & 1.4 & left renal dysplasia & p & TP & de novo \\
\hline 3 & $\operatorname{arr}[$ hg 19]17q12(34,822,465-36,243,365) × 1 & 1.4 & kidney echo enhancement & p & TP & de novo \\
\hline 4 & $\operatorname{arr}[$ hg19]17q12(34,822,465-36,307,773) $\times 1$ & 1.48 & kidney echo enhancement & $p$ & TP & de novo \\
\hline 5 & $\operatorname{arr}[$ hg19]17q12(34,822,465-36,404,555) × 1 & 1.58 & kidney echo enhancement & p & TP & de novo \\
\hline 6 & $\operatorname{arr}[$ hg19]17p12(14,083,054-15,482,833) × 1 & 1.4 & left renal agenesis & p & TP & Maternal \\
\hline 7 & $\begin{array}{l}\operatorname{arr}[\text { hg19]3q28(188,788,120-191,331,505) × 1,15q11.2 } \\
(23,620,191-24,978,547) \times 3\end{array}$ & $\begin{array}{l}2.5 \\
1.3\end{array}$ & right renal agenesis & p & TP & de novo \\
\hline 8 & $\operatorname{arr}[$ hg19]9q21.31q21.32 $(82,732,469-85,502,241) \times 1$ & 2.7 & left renal dysplasia & VUS & TD & de novo \\
\hline 9 & $\operatorname{arr}[$ hg19]2q31q34(111,859,545-209,533,369) × 2-3 & 97.9 & renal dysplasia & VUS & TD & de novo \\
\hline 10 & $\operatorname{arr}[\mathrm{hg} 19] 3$ p26.1 p24.1 $(8,494,626-26,413,121) \mathrm{hmz}$ & 17.9 & right renal agenesis & VUS & TD & $\begin{array}{l}\text { Not } \\
\text { reported }\end{array}$ \\
\hline
\end{tabular}

$P$ Pathogenic, TD Term delivery, TP Termination of pregnancy, VUS Variation of uncertain clinical significance

22q11.2 deletion, 4p16.3p15.1 deletion, and 7q11.23 duplication (Table 3 ).

\section{Inheritance analysis}

We screened the inheritance information of 14 families with abnormal CNVs (the parents of one case refused SNP-array test). The analysis showed that two fetuses inherited abnormal CNVs from unaffected parents, whereas 12 were de novo CNVs.

\section{Obstetrical outcomes and clinical follow-up}

We received delivery information from 120 pregnancies with RHD. Parental analysis showed that the abnormalities occurred de novo in 12 fetuses, CNV was inherited from unaffected parents in two cases, and the parents of one case refused SNP-array test. The reasons for the termination of pregnancies in the 11 women analyzed were pathogenic CNVs. We also found that one VUS CNV case (due to fetal URSMS) and two normal CNVs cases of RHD with extra-renal defects (due to severe fetal malformations) resulted in the termination of the pregnancy.
Clinical follow-up assessments and postpartum ultrasound were performed at 42 days after birth.

\section{Discussion}

Fetal malformations represent a poorly studied group of developmental disorders. The significant etiological heterogeneity of congenital kidney malformations cannot be detected by clinical evaluation, and because most structural variations are below the resolution of cytogenetic analysis, high-resolution genomic methods are required. Our objective was to assess the impact of CMA on the investigation of fetal congenital kidney malformations.

Many studies suggest that CNVs contribute to the etiology of RHD and implicate the genes within the CNV loci (e.g., PAX2, HNF1B, KIF26B, which are associated with kidney defects), that are detected in up to $10 \%$ of individuals with kidney malformations [9-12]. We detected 15 distinct known or novel CNVs in $12.5 \%$ of RHD cases, indicating a large proportion of rare pathogenic CNVs in fetal congenital kidney malformations. The overall diagnostic yield of $12.5 \%$ is lower than that

Table 3 Five abnormal copy-number variations detected in fetuses with non-isolated renal hypodysplasia

\begin{tabular}{|c|c|c|c|c|c|c|}
\hline case & CMA results & $\begin{array}{l}\text { Size } \\
(\mathrm{Mb})\end{array}$ & Prenatal ultrasound & $\begin{array}{l}\text { Pathogenicity } \\
\text { classification }\end{array}$ & $\begin{array}{l}\text { Obstetrical } \\
\text { outcomes }\end{array}$ & Inheritance \\
\hline 11 & $\operatorname{arr}[$ hg19]22q11.21 $(20,730,143-21,800,471) \times 1$ & 1.0 & $\begin{array}{l}\text { left renal dysplasia; Left choroid plexus } \\
\text { cyst; strephenopodia }\end{array}$ & $P$ & TP & de novo \\
\hline 12 & $\begin{array}{l}\text { arr[hg19]16q23.2q24.3 (79,800,878-90,146,366) } \\
\text { hmz,16p13.3p12.3 }(94,807-19,302,326) \mathrm{hmz}\end{array}$ & 10.3 & left renal agenesis; VSD; PVS; FGR & $p$ & TP & UPD \\
\hline 13 & $\operatorname{arr}[$ hg19]4p16.3p15.1 $(68,345-35,252,743) \times 1$ & 35 & $\begin{array}{l}\text { renal hypoplasia;FGR; nasal bone } \\
\text { dysplasia }\end{array}$ & $P$ & $\mathrm{TP}$ & de novo \\
\hline 14 & $\operatorname{arr}[$ hg19]7q11.23 $(72,701,098-74,069,645) \times 3$ & 1.3 & left renal agenesis, VSD; & $P$ & $\mathrm{TP}$ & de novo \\
\hline 15 & $\operatorname{arr}[$ hg19]16p13.11 $(15,325,072-16,272,403) \times 3$ & 0.92 & left renal dysplasia;URSMS & VUS & $\mathrm{TP}$ & de novo \\
\hline
\end{tabular}

FGR Fetal growth restriction, $p$ Pathogenic, PVS Pulmonary valve stenosis, TP Termination of pregnancy, UPD Uniparental disomy, URSMS Urorectal septum malformation sequence, VSD Ventricular septal defect, VUS Variation of uncertain clinical significance 
obtained with the use of CMA for the investigation of rare disorders in children or adults, which is $17.2 \%$ [3]. The lower rate of CMA for fetal congenital kidney malformations may be related to the involvement of epigenetic mechanisms or more complex genetic models.

Seven cases of pathogenic CNVs were related to kidney development in our study. The most frequent genomic imbalances that we detected in isolated RHD cases were $22 \mathrm{q} 11.2$ and $17 \mathrm{q} 12$ deletion. According to previous studies, congenital kidney, and urinary tract anomalies are present in approximately $30 \%$ of the patients with 22q11.21 deletion [13]. In this study, we found two cases with 22q11.21 deletion. Four cases had 17q12 deletion, their genomic regions involved hepatocyte nuclear factor 1 homeobox B (HNF1B), associated with renal cyst and diabetes (RCAD) syndrome [14]. We found two de novo pathogenic CNVs, a duplication in 15q11.2 and a deletion in 3q28, and identified two genes (TP63 and CLDN16). Per the literature [15], TP63 and CLDN16 genes are related to kidney development and developmental delay.

Four cases of pathogenic CNVs were likely related to kidney development. A deletion in 17p12 results in hereditary neuropathy with liability to pressure palsy [16]. According to the previous studies, there are no reports indicating that $17 \mathrm{p} 12$ deletion syndrome is related to RHD. Based on the DECIPHER database (http://www. sanger.ac.uk/PostGenomics/decipher/), DGV database (http://projects.tcag.ca/variation), and OMIM database (http://www.omim.org), 17p12 deletion was reported as clinically significant pathogenic CNVs. However, kidneyrelated genes were not found in chromosome 17p12. In one uniparental disomy case, the isodisomy in $16 \mathrm{q} 23.2 \mathrm{q} 24.3$ and 16p13.3p12.3 was detected, of size 19.2 Mb, and containing 179 OMIM genes. CMA on the parents revealed maternal uniparental disomy (UPD). Due to the used test we cannot exclude heterodisomy. Both heterodisomy and isodisomy can cause a disease if they affect a gene underlying genomic imprinting. In addition, isodisomy can result in functional loss to heterozygosity. Isodisomy which is inheritance of two copies of one parental chromosome, has same type of SNP sites results in the loss of heterozygosity can be detected according to the allele different lines. Heterodisomy inheritance of two homologous but genetically different chromosomes from one parent, unable to distinguish with only result of fetal. It can only be detected by pedigree linkage analysis. According to the UPD database (Liehr T. 2020. Cases with uniparental disomy. http://cs -tl.de/DB/CA/UPD/0-Start.html [accessed 01/01/2020]) and literatures [17], the UPD on Chr16 was identified with pathogenic CNVs and the phenotypes mainly included intrauterine growth retardation, cardiac malformation, and urinary system malformation. However, kidney-related genes were not identified in the UPD on Chr16. A de novo pathogenic deletion in $4 \mathrm{p}$ of $35 \mathrm{Mb}$ and containing 105 OMIM genes was identified. This region includes the key gene for Wolf-Hirschhorn syndrome (WHS). WHS is a well-known syndrome related to subtelomeric deletions in the short arm of chromosome 4 [18]. We also identified a $1.3 \mathrm{Mb}$ de novo duplication, resulting in $7 \mathrm{q} 11.23$ duplication syndrome. 7q11.23 duplication syndrome is caused by the reciprocal duplication of the 26 genes that are deleted in Williams syndrome. In the past few years, many cases with the classic 7q11.23 duplication syndrome have been reported in the literature [19-22]. These case reports have provided a detailed phenotypic description of $7 q 11.23$ duplication syndrome and highlighted its variability. Whether these four cases of pathogenic CNVs were related to RHD still needs more clinical data and biological function verification in the future.

Four VUS were identified that were likely related to kidney development. In the deletion of chromosome 9, TLE1 appears to be a gene of interest; it has also been reported as a risk factor for synovial sarcoma [23]. Further investigation is needed to determine whether this deletion has an effect on kidney development. The second VUS is a mosaicism of q13q34 region in chromosome 2 with a rate of about $58 \%$, and a duplication of the $97.9 \mathrm{Mb}$ fragment. Some reports have suggested the possibility that the overexpression of a gene(s) on q13q34 region in chromosome 2 may cause developmental delay and orofacial clefting [24]. The mosaicism of $\mathrm{q} 13 \mathrm{q} 34$ region in chromosome 2 has not been reported in the current literature, and our SNP-array test show that the parents of proband are normal. Therefore, the clinical significance of this $\mathrm{CNV}$ is not yet clear. The third VUS is a de novo duplication in 16p13.11. Although this variant does not explain the left renal dysplasia, it could be a risk factor for neurodevelopmental disorders and colorectal tumorigenesis [25, 26]. However, there are rare reports of $16 \mathrm{p} 13.11$ duplication casing a renal defect $[27,28]$. Whether or not 16p13.11 duplication is associated with renal development still needs to be further verified with larger samples. The fourth VUS is isodisomy (due to the used test we cannot exclude heterodisomy) in 3p26.1p24.1, of size $17.9 \mathrm{Mb}$ size and containing 83 OMIM genes. The isodisomy increases the risk of recessive genetic disease. The parents refused SNP-array test in the genes, so we defined the clinical implications of isodisomy in 3p26.1p24.1 as VUS variation.

We observed that eleven pregnant women with fetuses with pathogenic $\mathrm{CNVs}$ chose to terminate the pregnancy. One VUS CNV case (due to severe fetal URSMS) and two normal CNVs cases of RHD with extra-renal defects (due to severe fetal malformations) still 
terminated their respective pregnancies. The identification of pathogenic CNVs can improve genetic counseling, and raise the awareness of parents about RHD to reduce unnecessary terminations of pregnancy.

Owing to the retrospective nature of our study, it has some limitations. Determining the link between a CNV and the observed phenotype is complicated. Perhaps the application of some new genetic techniques could indicate the presence of other genetic anomalies that remained undetected. In addition, an important component of prenatal consultation for the patients is counseling on the long-term physical and mental development associated with RHD, which cannot be obtained from our study.

\section{Conclusion}

The clinical application of CMA plays an important role in the judgment of fetal prognosis. Parents are more inclined to terminate the pregnancy if the fetuses have pathogenic results of the SNP-array test. After CMA excluded the genetic diseases related to pathogenic CNVs in the fetus, fetal MRI is feasible to evaluate urinary systems such as fetal kidney, ureter, and bladder. Meanwhile, multidisciplinary cooperation is conducted with pediatric surgery to formulate a diagnosis and treatment plan for the fetus after birth.

\section{Abbreviations}

CAKUT: Congenital malformations of the kidney and urinary tract; CNVs: Copy number variations; CMA: Chromosomal microarray analysis; FGR: Fetal growth restriction; LOH: Loss of heterozygosity; FISH: Fluorescence in situ hybridization; PCR: Polymerase chain reaction; RHD: Renal hypodysplasia; SNP: Single nucleotide polymorphism; URSMS: Urorectal septum malformation sequence; UPD: Uniparental disomy; VUS: Variation of uncertain clinical significance

\section{Acknowledgments}

We thank the patients that participated in this study.

\section{Author's contributions}

Study concepts: Liangpu Xu, Yuan Lin; Study design: Meiying Cai; CMA analysis: Hailong Huang; Karyotyping: Xiaoqing Wu,Ying Li; FISH analysis: Hailong Huang; Data analysis and interpretation: Na Lin; Statistical analysis: Xiaorui Xie, Linjuan Su; Manuscript preparation:Meiying Cai, Liangpu Xu. All authors read and approved the final manuscript.

\section{Funding}

This work was supported by the Key Special Projects of Fujian Provincial Department of Science and Technology (no. 2013YZ0002-1); the Key Clinical Specialty Discipline Construction Program of Fujian (no. 20121589) and the Fujian Provincial Natural Science Foundation (no. 2017 J01238); Research fund project of Fujian Provincial Maternity and Children's Hospital, Grant/ Award Number:2018-31.

\section{Availability of data and materials}

The datasets used and/or analyzed during the current study are available from the corresponding author on reasonable request.

\section{Ethics approval and consent to participate}

The research was approved by the ethics committee at the Fujian Provincial Maternal and Child Health Hospital, and informed consent was obtained from the parents for invasive prenatal diagnosis.

\section{Consent for publication}

Informed written consent was obtained from parents for publication for. images and other clinical information relating to this case to be reported for. academic purpose.

\section{Competing interests}

The authors declare that they have no competing interest.

Received: 15 November 2019 Accepted: 17 March 2020

Published online: 24 March 2020

\section{References}

1. Livera LN, Brookfield DS, Egginton JA, Hawnaur JM. Antenatal ultrasonography to detect fetal renal abnormalities: a prospective screening programme. BMJ. 1989;298(6685):1421-3.

2. Sanna-Cherchi S, Ravani P, Corbani V, Parodi S, Haupt R, Piaggio G, et al Renal outcome in patients with congenital anomalies of the kidney and urinary tract. Kidney Int. 2009;76(5):528-33.

3. Sanna-Cherchi S, Kiryluk K, Burgess KE, Bodria M, Sampson MG, Hadley D, et al. Copy-number disorders are a common cause of congenital kidney malformations. Am J Hum Genet. 2012;91(6):987-97.

4. Barakat AJ, Drougas JG. Occurrence of congenital abnormalities of kidney and urinary tract in 13,775 autopsies. Urology. 1991;38(4):347-50.

5. Cai M, Lin N, Su L, Wu X, Xie X, Li Y, et al. Detection of copy number disorders associated with congenital anomalies of the kidney and urinary tract in fetuses via single nucleotide polymorphism arrays. J Clin Lab Anal. 2019;34:e23025

6. Cai M, Huang H, Su L, Lin N, Wu X, Xie X, et al. Chromosomal abnormalities and copy number variations in fetal ventricular septal defects. Mol Cytogenet. 2018;11:58

7. Hanemaaijer NM, Birgit SR, Gerben VDV, Trijnie D, Roel H, Essen AJ, et al. Practical guidelines for interpreting copy number gains detected by highresolution array in routine diagnostics. Eur J Hum Genet. 2012;20(2):161-5.

8. Valente AL, Tull J, Zhang S. Specificity of TLE1 expression in unclassified high-grade sarcomas for the diagnosis of synovial sarcoma. Appl Immunohisto M M. 2013;21(5):408-13.

9. Eccles MR, Schimmenti LA. Renal-coloboma syndrome: a multi-system developmental disorder caused by PAX2 mutations. Clin Genet. 1999; 56(1):1-9.

10. Thomas R, Sanna-Cherchi S, Warady BA, Furth SL, Kaskel FJ, Gharavi AG. HNF1B and PAX2 mutations are a common cause of renal hypodysplasia in the CKiD cohort. Pediatr Nephrol. 2011;26(6):897-903.

11. Ulinski T, Lescure S, Beaufils S, Guigonis V, Decramer S, Morin D, et al. Renal phenotypes related to hepatocyte nuclear factor-1beta (TCF2) mutations in a pediatric cohort. JASN. 2006;17(2):497-503.

12. Uchiyama $Y$, Sakaguchi M, Terabayashi $T$, Inenaga $T$, Inoue $S$, Kobayashi $C$, et al. Kif26b, a kinesin family gene, regulates adhesion of the embryonic kidney mesenchyme. P Natl Acad of Sci USA. 2010;107(20):9240-5.

13. Lopez-Rivera E, Liu YP, Verbitsky M, Anderson BR, Capone VP, Otto EA, et al. Genetic drivers of kidney defects in the DiGeorge syndrome. N Engl J Med. 2011;376(8):742-54

14. Lindner TH, Njolstad PR, Horikawa Y, Bostad L, Bell Gl, Sovik O. A novel syndrome of diabetes mellitus, renal dysfunction and genital malformation associated with a partial deletion of the pseudo-POU domain of hepatocyte nuclear factor-1beta. Hum Mol Genet. 1999;8(11):2001.

15. Konrad M, Schaller A, Seelow D, Pandey AV, Waldegger S, Lesslauer A, et al. Mutations in the tight-junction gene Claudin 19 (CLDN19) are associated with renal magnesium wasting. Renal failure, and severe ocular involvement. Am J Hum Genet. 2006:79(5):0-957.

16. Chance PF, Alderson MK, Leppig KA, Lensch MW, Matsunami N, Smith B, et al. DNA deletion associated with hereditary neuropathy with liability to pressure palsies. Cell. 1993;72(1):143-51.

17. Yingjun $X$, Zhiyang $H$, Linhua $L$, Fangming $S$, Linhuan $H$, Jinfeng $T$, et al. Chromosomal uniparental disomy 16 and fetal intrauterine growth restriction. Eur J Obstet Gyn R B. 2017;211:1-7

18. Hannelie E, Smagt JJ. Van Der, Ruben VTS, Vermeesch JR, Ron H, et al. wolfHirschhorn syndrome facial dysmorphic features in a patient with a terminal $4 p 16.3$ deletion telomeric to the WHSCR and WHSCR 2 regions. Eur J Hum Genet. 2009;17(1):129-32. 
19. Merritt JL, Lindor NM. Further clinical description of duplication of WilliamsBeuren region presenting with congenital glaucoma and brachycephaly. Am J Med Genet A. 2010;146A(8):1055-8.

20. Malenfant P, Liu X, Hudson ML, Qiao Y, Hrynchak M, Riendeau N, et al. Association of GTF2i in the Williams-Beuren syndrome critical region with autism Spectrum disorders. J Autism Dev Disord. 2012;42(7):1459-69.

21. Prontera P, Serino D, Caldini B, Scarponi L, Merla G, Testa G, et al. Brief report: functional MRI of a patient with 7q11.23 duplication syndrome and autism Spectrum disorder. J Autism Dev Disord. 2014;44(10):2608-13.

22. Ashley P, Jeanne J, Paula G, Hinton RB, Erin M, Amy S, et al. Aortopathy in the 7q11.23 microduplication syndrome. Am J Med Genet A. 2015; 167(2):363-70

23. Terry J, Saito T, Subramanian S, Ruttan C, Antonescu CR, Goldblum JR, et al. TLE1 as a diagnostic immunohistochemical marker for synovial sarcoma emerging from gene expression profiling studies. Am J Surg Pathol. 2007; 31(2):240

24. Zeiger JS, Hetmanski JB, Beaty TH, Vanderkolk CA, Wyszynski DF, BaileyWilson JE, et al. Evidence for linkage of nonsyndromic cleft lip with or without cleft palate to a region on chromosome 2. Eur J Hum Genet. 2003; 11(11):835-9.

25. Yen-Tsung H, Heist RS, Chirieac LR, Xihong L, Vidar S, Shanbeh Z, et al. Genome-wide analysis of survival in early-stage non-small-cell lung cancer. J Clin Oncol. 2009;27(16):2660-7.

26. Davis LK, Maltman N, Mosconi MW, Macmillan C, Schmitt L, Moore K, et al. Rare inherited A2BP1 deletion in a proband with autism and developmental hemiparesis. Am J Med Genet A. 2012;158A(7):1654-61.

27. Houcinat N, Llanas B, Moutton S, Toutain J, Cailley D, Arveiler B, et al. Homozygous 16p13.11 duplication associated with mild intellectual disability and urinary tract malformations in two siblings born from consanguineous parents. Am J Med Genet A. 2015;167A(11):2714-9.

28. Escobar LF, Weaver DD, Bixler D, Hodes ME, Mitchell M. Urorectal septum malformation sequence: report of six cases and embryological analysis. Am J Dis Child. 2015:141(9):1021.

\section{Publisher's Note}

Springer Nature remains neutral with regard to jurisdictional claims in published maps and institutional affiliations.

Ready to submit your research? Choose BMC and benefit from:

- fast, convenient online submission

- thorough peer review by experienced researchers in your field

- rapid publication on acceptance

- support for research data, including large and complex data types

- gold Open Access which fosters wider collaboration and increased citations

- maximum visibility for your research: over $100 \mathrm{M}$ website views per year

At $\mathrm{BMC}$, research is always in progress.

Learn more biomedcentral.com/submissions 